кандидат філологічних наук, доцент

(Львівський національний університет імені Івана Франка) taras pyts@ukr.net ORCID: $0000-0 \overline{0} 02-6055-3622$

\title{
НІМЕЦЬКА НАЗВА ЛЮДВИСАРА У ДЗЕРКАЛІ ПОЛЬСЬКИХ, УКРАЇНСЬКИХ І БІЛОРУСЬКИХ ПАМ'ЯТОК
}

Статтю присвячено дослідженню назви людвисара у німецьькій, польській, украйнській та білоруській мовах. Розглядається історія вивчення цієї назви ремісника, аналізуються ї̈ німецькі діалектні витоки $i$ форми поширення у слов'янських мовах на основі писемних пам'яток XIV-XVIII ст. Також звертається увага на графічну, фонетичну і морфологічну асиміляцію запозичення у слов'янських мовах.

Ключові слова: назва ремісника, запозичення, асиміляція, дисиміляція, німецькі діалекти, міжмовні контакти.

Людвисарем у давнину називали ремісника, що способом лиття виливав різні речі з металу - такі як надгробні плити, двері, пластику. Що стосується побутових речей, то, на відміну від конвисаря, він лише 3 металу або міді виготовляв менші пристрої і предмети - світильники, кільця, пряжки, наперстки, кадила тощо, відкриті посудини - кадоби, умивальники, чаші тощо.

Аналіз останніх досліджень і публікацій. Більшість мовознавців дотримуються думки, що п. ludwisarz / ludwiser, lodwisarz "ремісник, що займається литтям і обробкою предметів з бронзи, металу, міді і латуні", виникли унаслідок дисиміляції $r-r>l-r 3$ rotgiser, Hвн. Rot(h)giesser, утвореного 3 rot "червоний" і giessen "лити, відливати з металу" [1: 460; 2: 303; 3: 11; 4: 143; 5: 2: 72; 23]. Регресивна дисиміляція спорадично не відбулася у таких формах фіксації назви ремісника: rótgisarz / rutgiser [5: 2: 72], rodgi(e)ser / rodgisar(z) rotgisarz / rotgiser [6]. Однак В. Кестнер зазначає, що дисиміляція обох $r$ (r-r > r-l та r-r > 1-r) відома усім індогерманським мовам. Відповідно під питанням $\epsilon$ те, у якій мові вона відбулася - у польській (п. alkierz, balwierz, falbierz, ludwisarz, stularz ...) чи ще у німецькій, де вона також засвідчена [7: 58]. Також є думка, що на зміну першої голосної могло вплинути зближення 3 іменем Ludwik (16 ст.), що у 15 ст. мало також форму Lodwik, також п. lost > lust [1: 401, 435; 23]. Натомість В. Кестнер, вважає що слова з п. и замість свн. $\hat{o}$ (ambos, dunal, kluska, ludwisarz, lunar, rura ...) запозичено не з німецької літературної мови, а з діалектів, у яких $\hat{o} є$ закритим звуком і відповідно приймає забарвлення $u$. На його думку, це могло відбутися у сілезькому діалекті, де свн. $\hat{o}$ при збереженні довжини звуку перейшло в $\hat{u}$, а при вкороченні звуку - в $u$ [7: 32]. Субституцію $t>d$ у першому компоненті композита ludwisarz відзначає ще Г. Корбут [1: 439]. В. Кестнер також притримується думки, що у німецьких вихідних формах (також до landwera, mundklej ...) був глухий $t$ i пояснює, що його заміна на п. $d$ частково зумовлена регресивною асиміляцією у польській мові, що спричиняє дзвінкість глухих звуків перед дзвінкими [7: 71].

Другий компонент -giesser у польській мові перетворюється у -wisarz під впливом п. konwisarz [1: 401, 435; 3: 11; 4: 143; 5: 2: 72; 23]. Як вважає А. Брюкнер, перехідною ланкою для п. ludwisarz слугував п. lodgisar [2: 303]. Те, що свн. (нвн.) іе відповідає п. $i$. В Кестнер пояснює тим, що запозичення назви ремісника відбулося 3 середньонімецьких говорів, де у свн. період ie переходить в $\hat{l}$, тоді як у південнонімецьких діалектах зберігається дифтонг іе [7: 45].

В українській мові етимологію назви ремісника людвисар сформулював Р. Смаль-Стоцький, що вважає, що вона утворена з німецького складного слова, що у свою чергу походить з свн. rot "червоний" і giezen "лити, виливати метал" [8: 167]. Натомість білоруські мовознавці наполягають на посередництві польської мови (блр. людвисаръ < п. ludwisarz < нім. Rotgiesser) [9: 89; 10: 148].

Постановка проблеми. Таким чином, у поглядах мовознавців помітні розбіжності та сумніви у поглядах на те, у якій мові відбулася зміна голосної $o>u$ та дисиміляція обох $r$ (r-r $>$ r-l та r-r $>1-\mathrm{r})$ у назві ремісника? А також, чи справді зміна в особовій назві (Lodwik> Ludwik) впливає на формування п. lodwisarz?

Виклад основного матеріалу. Для з'ясування історії виникнення польської назви ливаря та іiі подальшого поширення на схід, вважаємо за необхідне звернутися до пам'яток німецьких діалектів, польської, української і білоруської мов. Так, початкова недисимільована форма назви засвідчена у польській мові з кінця XVI ст.: ... vcżynić twarz litą. Z bladłego mośiądzu / abo z miedźzi czerwonawey / nie

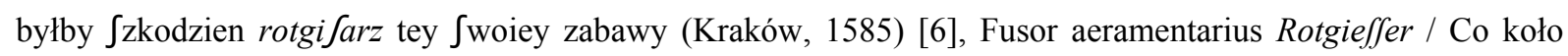
mofiądzu robi (Toruń, 1591), ... [11, т. XXXV, c. 308], inaczey baczemy ... w malar3ach / w ryfownikach, w

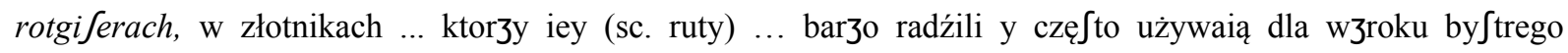


(Kraków, 1613) [18]. На століття раніше фіксується особова назва Georgius Rothgisser (Gniezno, 1475) [13: IV: 495]. Джерелом поширення вбачаємо східносередньонімецьке наріччя, де найменування ливаря задокументоване у верхньосаксонському говорі: Philipp Rotgisser (Zwickau, 1476), Rotgiesser (Zwickau, 1479) [14: 214]. Значно пізніше за польську особову назву найменування ремісника згадується також в тюринзькому діалекті: Lertz, Nicol, Rottgisser (Altenburg, 1556) [15: 44], Hans Langfeldt, RotgieЯer (Jena, 1596-1613) [5: 160], Jahn, Gerge, Rothgieser (Altenburg, 1652) [15: 139], Mьller, HanЯ, RothgieЯer (Altenburg, 1680) [15: 172], Rappe, Jacob, RotgieЯer (Erfurt, 1695) [17: 102]. Воно засвідчене також у назві вулиці м. Ерфурт: Unter den RotgieЯern (Erfurt, 1684, 1688) [17, с. 62, 63]. Ця назва ливаря була також відомою і у швабському говорі: Giesser von Metall / conflator, fusor ... Büchsengiesser ... Bildgiesser ... Rothgiesser ... Zingiesser (Augsburg, 1616) [12: 6: 2161].

Також у старопольській мові натрапляємо на форму цієї назви ремісника з першим компонентом rod-, що не має відповідника у німецьких діалектах: Item powyedzial ysch nieboszczik Rodgierzs Byenyak ... pyenyedzi vkradl (1548) [4: 198], Alexander rodgieser wiele mi złego wyrządził (1563), iako onemu rodgisarowi czo buł mosiądzowego wołu vcżynił tyrannowi (Kraków, 1568) [6], Rodgisarzu prozno formy gotuiesz gliniane ... (1585), Alexander mośiężnik rodgiffer abo kotlarz ... wiele mi złego pokazał (Kraków, 1593) [11: XXXV: 308]. У даному випадку відпрофесійне прізвисько також засвідчене майже на століття раніше за назву ливарника: Iohannes alias Hannus Rodgisser, civis Cracoviensis de platea Rotagorum (Kraków, 1455) [13: IV: 495]. Форма назви ремісника 3 першим компонентом rod- зазнає регресивної дисиміляції у польській мові, однак не фіксується у східнослов'янських: Bo Lodwisarz gdy leie obraz mośiężny / tedy gi nie złotym / ani nieśmiertelnym obrazem cżyni /ale zaś mośiężnym iako y był pierwey (Kraków, 1584) [11: 12: 303].

Іншою ще недисимільованою словоформою є Rutgisser, що нотується у польських джерелах: Rutgiser, co miedź sprawuje (Kraków, 1561) [23], Rutgifer co leie mośiądzowe rzeçy / v. Mośiądzem robiący (Kraków, 1643) [18]. Ї̈̈ еквівалент виявляємо у лаузіцькій говірці сілезького говору: Peter Rutgisser (Görlitz, 1431) [19: 114].

Час появи у польських пам'ятках дисимільованої форми назви ремісника 3 кореневою голосною $u$ збігається з фіксацією недисимільованої форми: u ludwisarki za nowym kierchowem długu fl. 30, na co jest zapis (Poznań, 1579) [11: XII: 345], Ludwiserowi od sprawienia lichtarza ... fl. 4 (Kraków, 1589) [11: XII: 303], Ludwisarzowi ... ad ronem roboty mieyskiey, Ludwisarzowi, co klin spizowy odlewał (Sądecczyzna, 1637) [20,

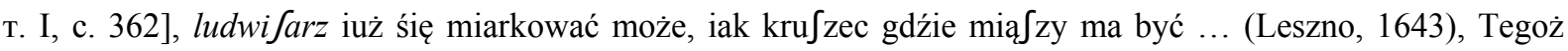
pomieniony Ludwifsarz odiechał w podruze sw[ą] (1730-1731), Bywaią to czasem Rzemieślnicy lub ich nazwießz Snycerzami, lub Ludwifarzami, lub tam Kowalami, czy Złotnikami, umieią fobie wyrznąć twarz, lub

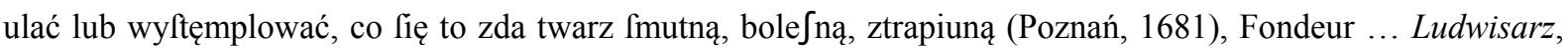

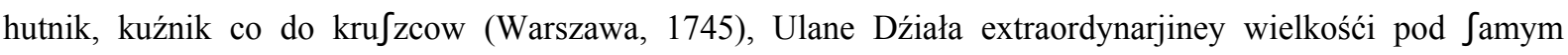

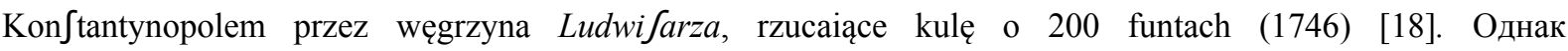
недисимільовані форми виходять з ужитку вже у першій половині XVII ст., а форма ludwisarz використовувалася ще у першій половині XIX ст. у Підляському воєводстві і, із зникненням відповідного ремесла, стає архаїзмом [6].

Виходячи $з$ даних німецької історичної діалектології, цілком очевидним є те, що в основі польських форм фіксацій назв ливарів і відпрофесійних прізвиськ лежать дві німецькі словоформи Rotgi(e)sser i Rutgisser чим пояснюється наявність голосних $о$ та $u$ у першому компоненті назви ремісника. А хронологія фіксації різних польських словоформ свідчить про те, що регресивна асиміляція (нім. rot- $>$ п. rod- (частково зберігається rot-), rut- > lud-) передувала регресивній дисиміляції (r-r > l-r). Зважаючи на те, що пам'ятки польської мови фіксують словоформи 3 rot-, rod-, lod- логічно припустити, що проміжною ланкою між п. rutgiser і ludwiser був *rudgiser. На зміну другого компонента -gis(s)er / -gisarz в -wiser / -wisarz, що у назві ливаря нотується з кінця XVI ст., через подібність способу виготовлення виробів цілком могло вплинути зближення 3 найменуванням іншого ливаря - konwisarz "майстер 3 виготовлення олов'яного литва", що фіксується майже на століття раніше, який, на відміну від ludwisarz, утворений шляхом фонетичного зближення і злиття рнвн. kanngisser "конвисар" та п. konwi "кінви" [21]. Також необхідно зазначити, шо словоформа lodgisar згадується лише в етимологічних словниках польської мови А. Брюкнера і А. Баньковського. Перший вказує, що вона згадується у творах М. Рея, польського поета, прозаїка і перекладача XVI ст.

Засвідчене відпрофесійне прізвисько Rodgierzs є двоскладовим на відміну від rodgieser / rodgisar. Очевидно вже у польській мові відбувається редукція $е$ чи $а$ у суфіксі (-er/-ar) і злиття його з попереднім складом. Також можна припустити, що в основі польського прізвиська німецька безсуфіксна форма фіксації німецької назви ремісника (*rodgiss). Подібний приклад також задокументовано у прізвиську Kangissz / Cangissz, що має відповідник у гессенському говорі: des kangißer bruder der kangiß (Grünberg, 1445) [22: 27]. 
Саме дисимільована форма найменування ливаря, очевидно через більш широке і триваліше поширення у польській мові, поширюється також і в українській мові: Пану Андрееви, людвисарови, который был до направованя звона (1654), ... оповьдане противъ Якова Афанасовича Пузынына, людвисара (Стародуб, 1693-1699), ... в Новгородку Сђверскомъ Иванъ Андриевичъ людвисаръ новгородски (1698) [23]. Також є одне свідчення у білоруських пам'ятках: Людвисаръ (1695) [10: 148].

На польському грунті назва ремісника зазнала певних графічних модифікацій. Так у польській мові зникає німецьке подвоєне ss на користь $s / \int:$ rodgiffer > rodgieser, rodgisar(z), lodwisarz; ludwifsarz > ludwifarz, що передається укр. і блр. людвисаръ. Німецьке $i(e)$ передається як п. $i$.

Водночас свідками фонетичних перетворень у польській мові $\epsilon$ : а) регресивна асиміляція $\operatorname{tg}>d g$ (п. rotgieffer, rotgifer, rotgifarz > rodgiffer, rodgieser, rodgisar(z); rutgiser > ludwiser); б) регресивна дисиміляція $r-r>$ l-r (п. rodgisar(z) > lodwisarz; rutgiser > ludwiser, ludwif(s)arz); в) субституція $g>w$ (п. rotgieffer, rotgifer, rotgifarz, rodgiffer, rodgieser, rodgisar(z)>lodwisarz; п. rutgiser > ludwiser, ludwif(s)arz). Морфологічна зміна відбулася у суфіксі -er, що змінюється на -ar(z) (rotgieffer, rotgifer > rotgifarz;

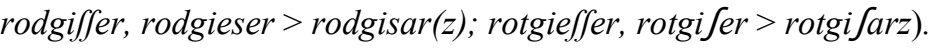

Після усіх цих численних перетворень назва ремісника, що займався литтям і обробкою предметів 3 бронзи, металу, міді і латуні 3 польської мови поширюється в українській та білоруській мовах (людвисаръ). В обох мовах для позначення сполучення м'якого приголосного л 3 у використовується голосний ю, польський суфікс -ar(z) трансформувався в -ap, а твердість приголосного $p$ позначається додатково через $b$. Але у білоруській мові $u$ реалізується як [i], а в українській - як [и]. Тобто 3 початкових німецьких літер залишилися лише приголосні $c$ (ss) i $p(r)$.

Висновки. Отже, можна стверджувати, що у слов'янські мови поширилися як апелятив та антропонім дві німецькі варіантні форми назви ремісника, що займається литтям і обробкою предметів з бронзи, металу, міді і латуні: рнвн. Rotgi(e)sser (> п. rotgieffer, rotgifer, rotgifarz > rodgiffer, rodgieser, rodgisar(z) $>$ lodwisarz; Rothgisser, Rodgisser) і Rutgisser (> п. rutgiser > ludwiser, ludwi (s)arz > укр., блр. людвисаръ). Обидві є східносередньонімецького походження, друга можливо - лише сілезького. А дисиміляція обох $r$ (r-r > r-1 та r-r > 1-r) у назві ремісника відбулася вже у польській мові і передалася східнослов’янським. Щодо Rodgierzs нема певності, що лежить в основі прізвиська - безсуфіксна форма *rodgiss чи таки Rotgi(e)sser.

\section{СПИСОК ВИКОРИСТАНИХ ДЖЕРЕЛ ТА ЛІТЕРАТУРИ}

1. Korbut G. Wyrazy niemieckie w języku polskim pod względem językowym i cywilizacyjnym / Gabriel Korbut // Prace Filologiczne. - Warszawa, 1893. - T. IV. - S. 345-560.

2. Brückner A. Słownik etymologiczny języka polskiego / Alexander Brückner. - Warszawa : Wiedza Powszechna, 1985. $-805 \mathrm{~s}$.

3. Frenzel M. Die Handwerkerbezeichnungen im Westslawischen : Diss. ... des Doktorgrades / Maria Frenzel. Berlin, 1969. - $195 \mathrm{~S}$.

4. Symanzik B. Die alt- und mittelpolnischen Handwerkerbezeichnungen : Onomasiologisch-semasiologische Studien unter Berücksichtigung wissenschaftlicher Aspekte / Bernhard Symanzik. - Münster-Hamburg, 1993. - 439 S.

5. Bańkowski A. Etymologiczny słownik języka polskiego / Andrzej Bańkowski. - Warszawa : PWN, 2000. - T. 1 2.

6. Vincenz A. de. Wörterbuch der deutschen Lehnwörter in der polnischen Schrift- und Standardsprache : Von den Anfängen des polnischen Schrifttums bis in die Mitte des 20. Jahrhunderts [Електронний ресурс] / Andre de Vincenz, Gerd Hentschel. - Режим доступу до словника: http://www.bis.uni-oldenburg.de/bisverlag/wdlp/46701.html.

7. Kaestner W. Die deutschen Lehnwörtern im Polnischen, 1. Teil: Einleitung und Lautlehre: Diss. ... des Doktorgrades / Walter Kaestner. - Leipzig, 1939. - 131 S. + XXVIII.

8. Smal-Stockyj R. Die germanisch-deutschen Kultureinflüsse im Spiegel der ukrainischen Sprache/ Roman SmalStockyj. - Leipzig : Hirzel, 1942. - 282 S.

9. Булыка А. М. Лексічныя запазычанні ў беларускай мове XIV - XVIII стст. / А. М. Булыка. - Мінск : Навука і тэхніка, 1980. - $256 \mathrm{c.}$

10. Гарбачык М. Р. Назвы асоб па рамяству і прафесії ў беларускай мове : дисс. ... канд. філал. навук : 10.02.02 / Гарбачык Мікалай Рыгоравіч. - Мінск, 1992. - 240 с.

11. Słownik polszczyzny XVI wieku / [red. M. R. Mayenowa, F. Pepłowski, K. Mrowcewicz, P. Potoniec]. Wrocław-Kraków-Warszawa, 1966 - 1976. - T. I-X.

12. Frühneuhochdeutsches Wörterbuch / [hrsg. von Robert A. Anderson, Ulrich Goebel, Oskar Reichmann]. - BerlinNew York, 1989 - 2017. - Bd. 1-11.

13. Słownik staropolskich nazw osobowych / [red. W. Taszycki]. - Wrocław-Kraków-Warszawa, 1965 - 1985. - T. I - VII.

14. Hellfritzsch V. Personennamen Südwestsachsens. Die Personennamen der Städte Zwickau und Chemnitz / Volkmar Hellfritzsch. - Leipzig, 2007. - 702 S. 
15. Heinzig Fr. Die Bürgerbücher der Stadt Altenburg in Thüringen 1512-1700 / Frank Heinzig, Wilfried Köhler, Heidemarie Mattis. - Marburg, 2008. - 280 S.

16. Apel H. Jenas Einwohner aus der Zeit von 1250 bis 1600. Quellenbuch zur Jenaer Sippengeschichte / Hans Apel. Görlitz, 1937. - 314 S.

17. Bauer M. Bürgerbuch der Stadt Erfurt 1670-1760 / Martin Bauer. - Marburg, 2002. - 536 S.

18. Kartoteka Słownika języka polskiego XVII i 1. połowy XVIII wieku [Електронний ресурс]. - Режим доступу до картотеки : http://www.rcin.org.pl/publication/20029.

19. Bahlow H. Schlesisches Namenbuch / Hans Bahlow. - Kitzingen : Holzner, 1953. - 147 S.

20. Bubak J. Słownik nazw osobowych i elementów identyfikacyjnych Sądecczyzny XV-XVII w. (imiona, nazwiska, przezwiska) / Jósef Bubak. - Kraków, 1992. - Cz. 1-2.

21. Пиц Т. Б. Німецька назва конвісара у дзеркалі польських, українських та білоруських пам'яток / Т. Б Пиц // Мовознавство. - 2018. - № 1. - С. 49-58.

22. Knauß O. Die Entstehung der Grünberger Familiennamen / Otto Knauß. - Gießen, 1940. - 107 S.

23. Картотека історичного словника українського язика. Зберігається в інституті українознавства ім. І. Крип'якевича у Львові.

\section{REFERENCES (TRANSLATED \& TRANSLITERATED)}

1. Korbut G. Wyrazy niemieckie w języku polskim pod względem językowym i cywilizacyjnym / Gabriel Korbut // Prace Filologiczne. - Warszawa, 1893. - T. IV. - S. 345-560.

2. Brückner A. Słownik etymologiczny języka polskiego / Alexander Brückner. - Warszawa : Wiedza Powszechna, 1985. $-805 \mathrm{~s}$

3. Frenzel M. Die Handwerkerbezeichnungen im Westslawischen : Diss. ... des Doktorgrades / Maria Frenzel. Berlin, 1969. - $195 \mathrm{~S}$.

4. Symanzik B. Die alt- und mittelpolnischen Handwerkerbezeichnungen : Onomasiologisch-semasiologische Studien unter Berücksichtigung wissenschaftlicher Aspekte / Bernhard Symanzik. - Münster-Hamburg, 1993. - 439 S.

5. Bańkowski A. Etymologiczny słownik języka polskiego / Andrzej Bańkowski. - Warszawa : PWN, 2000. - T. 1 2 .

6. Vincenz A. de. Wörterbuch der deutschen Lehnwörter in der polnischen Schrift- und Standardsprache : Von den Anfängen des polnischen Schrifttums bis in die Mitte des 20. Jahrhunderts [Електронний ресурс] / Andre de Vincenz, Gerd Hentschel. - Available at : http://www.bis.uni-oldenburg.de/bis-verlag/wdlp/46701.html

7. Kaestner W. Die deutschen Lehnwörtern im Polnischen, 1. Teil: Einleitung und Lautlehre : Diss. ... des Doktorgrades / Walter Kaestner. - Leipzig, 1939. - 131 S. + XXVIII.

8. Smal-Stockyj R. Die germanisch-deutschen Kultureinflüsse im Spiegel der ukrainischen Sprache / Roman SmalStockyj. - Leipzig : Hirzel, 1942. - 282 S.

9. Bulyka A. M. Leksichnyya zapazychanni u belaruskay move XIV - XVIII stst. [Lexikal Borrowings in Byelorussian of the XIV - XVIII Centuries] / Alaksandr Mikalayevich Bulyka. - Minsk, 1980. - $256 \mathrm{~s}$.

10. Harbachyk M. R. Nazvy asob pa ramyastvu i prafesiyi u belaruskay move [Trade and Occupational Names in Byelorussian] : dys ... kand. filal. navuk : 10.02.02 / Harbachyk Mikalay Rygoravich. - Minsk, 1992. - $240 \mathrm{~s}$.

11. Słownik polszczyzny XVI wieku / [red. M. R. Mayenowa, F. Pepłowski, K. Mrowcewicz, P. Potoniec]. Wrocław-Kraków-Warszawa, 1966 - 1976. - T. I - X.

12. Frühneuhochdeutsches Wörterbuch / [hrsg. von Robert A. Anderson, Ulrich Goebel, Oskar Reichmann]. - BerlinNew York, $1989-2017 .-$ Bd. $1-11$.

13. Słownik staropolskich nazw osobowych / [red. W. Taszycki]. - Wrocław-Kraków-Warszawa, $1965-1985$. - T. I - VII.

14. Hellfritzsch V. Personennamen Südwestsachsens. Die Personennamen der Städte Zwickau und Chemnitz / Volkmar Hellfritzsch. - Leipzig, 2007. - 702 S.

15. Heinzig Fr. Die Bürgerbücher der Stadt Altenburg in Thüringen 1512-1700 / Frank Heinzig, Wilfried Köhler, Heidemarie Mattis. - Marburg, 2008. - 280 S.

16. Apel H. Jenas Einwohner aus der Zeit von 1250 bis 1600. Quellenbuch zur Jenaer Sippengeschichte / Hans Apel. Görlitz, 1937. - 314 S.

17. Bauer M. Bürgerbuch der Stadt Erfurt 1670-1760 / Martin Bauer. - Marburg, 2002. - 536 S.

18. Kartoteka Słownika języka polskiego XVII i 1. połowy XVIII wieku [Electronic resource]. - Available at: http://www.rcin.org.pl/publication/20029.

19. Bahlow H. Schlesisches Namenbuch / Hans Bahlow. - Kitzingen : Holzner, 1953 - 147 S.

20. Bubak J. Słownik nazw osobowych i elementów identyfikacyjnych Sądecczyzny XV-XVII w. (imiona, nazwiska, przezwiska) / Jósef Bubak. - Kraków, 1992. - Cz. 1-2.

21. Pyts T. B. Nimets'ka nazva konvisara u dzerkali pol's'kykh, ukrains'kykh ta bilorus'kykh pamyatok [The German Name of Pewterer in the Mirror of Polish, Ukrainian and Byelorussian Written Recollections] / T. B. Pyts // Movoznavstvo [Linguistics]. - 2018. - Nr. 1. - S. 49-58.

22. Knauß O. Die Entstehung der Grünberger Familiennamen / Otto Knauß. - Gießen, 1940. - 107 S.

23. Kartoteka istorychnoho slovnyka ukrayinskoho yazyka. Zberihayetsya $\mathrm{v}$ instytuti ukrayinoznavstva im. I. Krypjakevycha u Lvovi [Card Index of the Historical Dictionary of Ukrainian Language. Maintained at the I. Krypiakevych Institute of Ukrainian Studies in Lviv]. 
Пыц Т. Б. Немецкое название литейщика в зеркале польских, украинских и белорусских источников.

Статья посвящается исследованию названия литейщика Rotgießеr в немеиком, польском, украинском и белорусском языках. Рассматривается история изучения этого названия ремесленника, анализируются его диалектные источники и формы распространения в славянских языках на основании письменных памятников XIV-XVIII cm. Также уделяется внимание графической, фонетической и морфологической ассимиляции заимствования в славянских языках.

Ключевые слова: название ремесленника, заимствование, ассимиляџия, диссимиляция, немецкие диалекты, межъязыковые контакты.

\section{Pyts T. B. German Name of Red Brass Founder in the Mirror of Polish, Ukrainian and Byelorussian Written Recollections.}

The paper is dedicated to the research of name of the red brass founder (Rotgießer) in German, Polish, Ukrainian, Byelorussian. The history of research of etymology of P. ludwisarz, rodgisarz (and also their wordforms), Ukr. and Byel. людвисарь is analyzed. As a result, there are considerable discrepancies in the views of linguists in the question, in which language the change of the loud $o>u$ and the dissimilation of both $r$ in the handicraft name occurred, and indeed the change in the personal name Lodwik $>$ Ludwik affects the formation of P. lódwisarz. On the basis of written recollection of German, Polish, Ukrainian and Belarusian languages of the XV-XVIII centuries it is established, that in the East German dialects of the XV century coexisted simultaneously two forms of the handicraft name Rotgießer and Rutgießer, that the Polish language borrowed. Here happened a regressive assimilation (germ. rot $>$ p. rod) and regressive dissimilation ( $r-r>l-r)$. The change of the second component-giesser $>$-wisarz was influenced by the presence in Polish of another borrowed from the German language the name of the casting - konwisarz "pewterer", which is referred in Polish sources to the $X V$ century as a surname and handicraft name. After phonetic transformations, the name of casting is borrowed in Ukrainian and Belarusian languages, where it also undergoes minor phonetic and graphic transformations.

Polish sources also capture the disyllabic nickname Rodgierzs, but it is not sure, what is the base of the nickname-a form without suffix *rodgiss or Rotgi(e)sser.

Key words: handicraft name, loan word, assimilation, dissimilation, German dialect, languages in contact. 